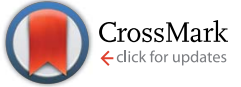

Cite this: RSC Adv., 2017, 7, 2943

Received 1st November 2016 Accepted 4th December 2016

DOI: 10.1039/c6ra26110h

www.rsc.org/advances

\section{Facile synthesis of $\mathrm{Bi}_{2} \mathrm{MoO}_{6}-\mathrm{MIL-100}(\mathrm{Fe})$ metal-organic framework composites with enhanced photocatalytic performance}

\author{
Jia Yang, ${ }^{\text {abc }}$ Xiaojun Niu, ${ }^{\text {abcd }}$ Shaorong An, ${ }^{\text {abc }}$ Weiyi Chen, ${ }^{\text {abc }}$ Jie Wang ${ }^{\text {abc }}$ \\ and Wei Liu abc
}

A novel $\mathrm{Bi}_{2} \mathrm{MoO}_{6}-\mathrm{MIL}-100(\mathrm{Fe})$ heterostructure photocatalyst was synthesized by a facile solvothermal method for the first time, and characterized by X-ray diffraction, scanning electron microscopy, X-ray photoelectron spectroscopy, UV-vis diffuse reflectance spectra, transmission electron microscopy, and photoluminescence spectra. The as-prepared $\mathrm{Bi}_{2} \mathrm{MoO}_{6}-\mathrm{MIL}-100(\mathrm{Fe})$ composites exhibited excellent photocatalytic activity and stability towards the degradation of Rhodamine $B(\mathrm{RhB})$ under visible light irradiation. The introduction of $\mathrm{MIL}-100(\mathrm{Fe})$ into semiconductor $\mathrm{Bi}_{2} \mathrm{MoO}_{6}$ improved the photocatalytic performance remarkably, and the optimal composite with 9\% MIL-100(Fe) content showed the highest photocatalytic activity. According to the active radical trapping experiments, the $\mathrm{h}^{+}$and ${ }^{\cdot} \mathrm{O}_{2}{ }^{-}$radicals were the two main active species in the photocatalytic reaction. The enhanced photocatalytic performance is mainly attributed to the formation of the $\mathrm{Bi}_{2} \mathrm{MoO}_{6}-\mathrm{MIL}-100$ (Fe) heterostructure, which is beneficial to the transfer and separation of photo-generated electron-hole pairs. The possible mechanism of the enhanced photocatalytic performance of the $\mathrm{Bi}_{2} \mathrm{MoO}_{6}-\mathrm{MIL}-100(\mathrm{Fe})$ composites was discussed.

\section{Introduction}

The semiconductor photocatalysis technique has attracted extensive attention in the splitting of water and the degradation of organic pollutants using sunlight as the energy source. ${ }^{1}$ Among the various photocatalysts, $\mathrm{TiO}_{2}$ is an attractive photocatalyst, because of its low toxicity, high photocatalytic activity and long term chemical stability. ${ }^{2-4}$ However, the applications of $\mathrm{TiO}_{2}$ are severely limited, owing to it only being excited by ultraviolet (UV) light which accounts for less than $5 \%$ of the solar spectrum. Therefore, many reports are focused on developing visible light responsive photocatalytic materials to replace $\mathrm{TiO}_{2}$, such as $\mathrm{Bi}_{2} \mathrm{MoO}_{6},{ }^{5} \mathrm{In}_{2} \mathrm{O}_{3},{ }^{6} \mathrm{Ag}_{3} \mathrm{PO}_{4},{ }^{7}$ and $\mathrm{g}-\mathrm{C}_{3} \mathrm{~N}_{4}$ (ref. 8) photocatalysts.

$\mathrm{Bi}_{2} \mathrm{MoO}_{6}$ is a typical Aurivillius oxide, exhibited excellent photocatalytic activity under the visible light irradiation. ${ }^{9}$ Compared with $\mathrm{TiO}_{2}, \mathrm{Bi}_{2} \mathrm{MoO}_{6}$ has a lower band gap (2.5-

${ }^{a}$ School of Environment and Energy, College of Environment and Energy, South China University of Technology, Guangzhou, 510006, China. E-mail: xjniu@scut.edu.cn; Fax: +86-20-3934-9919; Tel: +86-20-3934-9919

${ }^{b}$ Guangdong Provincial Key Laboratory of Atmospheric Environment and Pollution Control, South China University of Technology, Guangzhou Higher Education Mega Centre, Guangzhou 510006, PR China

${ }^{c}$ The Key Lab of Pollution Control and Ecosystem Restoration in Industry Clusters, Ministry of Education, South China University of Technology, Guangzhou Higher Education Mega Centre, Guangzhou 510006, PR China

${ }^{d}$ The State Key Laboratory of Lake Science and Environment, Nanjing Institute of Geography and Limnology, Chinese Academy of Sciences, Nanjing, 210008, PR China
$2.8 \mathrm{eV}$ ), which makes it utilize more sunlight and displays remarkable photocatalytic performance for organic pollutant degradation under visible light irradiation. ${ }^{\mathbf{1 0}}$ However, the practical application of the pure phase $\mathrm{Bi}_{2} \mathrm{MoO}_{6}$ is limited by its poor quantum yield, which is caused by the rapid recombination of photoinduced charge carriers. To further improve the photocatalytic activity of $\mathrm{Bi}_{2} \mathrm{MoO}_{6}$, many feasible methods have been explored, including designing textural properties, doping composites ${ }^{11,12}$ and combining with other semiconductors, ${ }^{13-15}$ carbon materials ${ }^{16}$ or noble metals. ${ }^{17}$ Nevertheless, there is still plenty of space to explore unfulfilled potentials for fabricating $\mathrm{Bi}_{2} \mathrm{MoO}_{6}$-based photocatalysts.

Metal-organic frameworks (MOFs) are an extensive class of crystalline materials formed by the self-assembly between metal ions and organic ligands. ${ }^{18}$ Recently, they have obtained extensive attention owing to their huge potential applications in sensing, ${ }^{19}$ gas storage ${ }^{20}$ drug delivery, ${ }^{21}$ optical properties ${ }^{22}$ and catalysis. These MOFs composites can act as catalysts, using unsaturated metal sites and catalytically active organic likers. ${ }^{23,24}$ Additionally, MOFs exhibit tunable photo-physical and photo-chemical properties, it can work well as excellent candidates for photocatalysis. For example, Dan-Hardi et al. synthesized a new photoactive crystalline titanium dicarboxylate (MIL-125(Ti)), which exhibits high photonic sensitivity under UV-visible irradiation. ${ }^{25}$ Hou Wang et al. had reported that $\mathrm{In}_{2} \mathrm{~S}_{3} @ \mathrm{MIL}-125(\mathrm{Ti})$ can remove the tetracycline by adsorption and photocatalysis. These reports showed that some MOFs can 
be applied in photocatalysis. ${ }^{26}$ Compared with traditional semiconductor photocatalysts, the superiority of MOFs is their ultrahigh surface area and narrow micropore distribution which may lead to the formation of monodisperse photoactive species supported on MOFs. ${ }^{27}$ Recently, several semiconductor@MOF heterostructures like CdS@MIL-100(Fe), ${ }^{28}$ CdS@UiO-66 $\left(\mathrm{NH}_{2}\right),{ }^{18} \mathrm{ZnO} @ Z I F-8,{ }^{29}$ and GaN@ZIF-8 (ref. 30) have been synthesized and exhibited excellent catalytic performance due to their synergistic effect. However, the photocatalytic performance of $\mathrm{Bi}_{2} \mathrm{MoO}_{6}-\mathrm{MOF}$ composites, to the best of our knowledge, has not been investigated.

Herein, we report a novel $\mathrm{Bi}_{2} \mathrm{MoO}_{6}-\mathrm{MIL}-100(\mathrm{Fe})$ composite that shows excellent photocatalytic activity in degradation organic pollutants. A series of $\mathrm{Bi}_{2} \mathrm{MoO}_{6}-\mathrm{MIL}-100(\mathrm{Fe})$ composites with different weight addition ratios of MIL-100(Fe) have been successfully synthesized via a facile solvothermal method. The photocatalytic performance was evaluated by the degradation of Rhodamine B under visible light irradiation. The combination of MIL-100(Fe) remarkably improved the photostability and the photocatalytic efficiency of the photocatalyst for degradation RhB. Furthermore, the possible mechanism of the enhanced photocatalytic performance of the $\mathrm{Bi}_{2} \mathrm{MoO}_{6}-\mathrm{MIL}-100(\mathrm{Fe})$ composite was discussed.

\section{Experimental}

\subsection{Materials}

Bismuth nitrate pentahydrate, sodium molybdate dehydrate were obtained from Tianjin Kemiou Chemical Reagent Co., Ltd. (Tianjin, China), benzene-1,3,5-tricarboxylic acid $\left(\mathrm{H}_{3} \mathrm{btc}\right)$ and $\mathrm{Fe}$ powder were purchased from Aladdin Industrial Corporation (Shanghai, China). Ethylene glycol (EG), and ethanol (EtOH) were purchased from Sinopharm Chemical Reagent Co., Ltd. (Shanghai, China). All chemicals were analytic grade and used without further purification.

\subsection{Preparation of MIL-100(Fe)}

According to the previous literature, ${ }^{31,32}$ MIL-100(Fe) was prepared by solvothermal method. In detail, a mixture of $\mathrm{Fe}$ powder with $\mathrm{H}_{3}$ btc, $\mathrm{HF}, \mathrm{HNO}_{3}$ and $\mathrm{H}_{2} \mathrm{O}$ with a molar ratio of $1: 0.67: 2: 0.6: 2.77$ was synthesized in a Teflon-lined stainless steel autoclave at $150{ }^{\circ} \mathrm{C}$ for $24 \mathrm{~h}$. Then the orange solid was centrifuged, washed with ethanol and hot water for several times, and finally dried overnight $60{ }^{\circ} \mathrm{C}$ under vacuum.

\subsection{Synthesis of $\mathrm{Bi}_{2} \mathrm{MoO}_{6}-\mathrm{MIL}-100(\mathrm{Fe})$ composite}

The as-prepared MIL-100(Fe) with the desired weight addition was dispersed in $10 \mathrm{~mL}$ ethanol by ultrasonication to gain the homogeneous MIL-100(Fe)-EtOH dispersion. Next, $2 \mathrm{mmol}$ $\mathrm{Bi}\left(\mathrm{NO}_{3}\right)_{3} \cdot 5 \mathrm{H}_{2} \mathrm{O}$ and $1 \mathrm{mmol} \mathrm{Na} \mathrm{MoO}_{4} \cdot 2 \mathrm{H}_{2} \mathrm{O}$ dissolved in $20 \mathrm{~mL}$ ethylene glycol were dropwised into MIL-100(Fe)-EtOH dispersion. After being stirred for $30 \mathrm{~min}$ at room temperature, the mixed solution was transferred into a $50 \mathrm{~mL}$ Teflon-lined stainless steel autoclave and kept at $160{ }^{\circ} \mathrm{C}$ for $12 \mathrm{~h}$. Finally, the obtain samples were collected, washed with deionized water and ethanol, dried overnight at $60{ }^{\circ} \mathrm{C}$ under vacuum. According to the method, as-synthesized composites with expected MIL$100(\mathrm{Fe})$ contents of $3,6,9$ and $12 \%$ were synthesized and named as $\mathrm{Bi}_{2} \mathrm{MoO}_{6}-\mathrm{MIL}-100(\mathrm{Fe})-3, \mathrm{Bi}_{2} \mathrm{MoO}_{6}-\mathrm{MIL}-100(\mathrm{Fe})-6$, $\mathrm{Bi}_{2} \mathrm{MoO}_{6}-\mathrm{MIL}-100(\mathrm{Fe})-9$ and $\mathrm{Bi}_{2} \mathrm{MoO}_{6}-\mathrm{MIL}-100(\mathrm{Fe})-12$, respectively. For comparison, the $\mathrm{Bi}_{2} \mathrm{MoO}_{6}-\mathrm{MIL}-100(\mathrm{Fe})$ physical mixture composites were synthesized by simple mechanical mixture, and named as $\mathrm{Bi}_{2} \mathrm{MoO}_{6}-\mathrm{MIL}-100(\mathrm{Fe})-9(\mathrm{M})$. As a control, pure $\mathrm{Bi}_{2} \mathrm{MoO}_{6}$ was also prepared in ethanol under the same reaction conditions as that of $\mathrm{Bi}_{2} \mathrm{MoO}_{6}-\mathrm{MIL}-100(\mathrm{Fe})$ composites except for the addition of MIL-100(Fe).

\subsection{Characterization}

X-ray diffraction (XRD) patterns of all samples were carried out using an Empyrean diffractometer (PANalytical B.V., Netherlands), with $\mathrm{Cu} \mathrm{K} \alpha$ radiation $(\lambda=1.54184 \AA)$ in the $2 \theta$ range of $10-80^{\circ}$. The morphologies and microstructures of the products were characterized by a Merlin field emission scanning electron microscope (FE-SEM, Zeiss). Transmission electron microscopy (TEM) images and high-resolution transmission electron microscopy (HRTEM) images were obtained by FEI Tecnai G2 F20 microscope at an accelerating voltage of $200 \mathrm{kV}$. The Brunauer-Emmett-Teller (BET) surface area was examined by nitrogen adsorption-desorption isotherm at $77 \mathrm{~K}$ on Micromeritics Instrument 3Flex adsorption analyzer. X-ray photoelectron spectroscopy (XPS) was performed on a Thermo Escalb 250Xi spectrometer with a monochromatic $\mathrm{Al}(\mathrm{K} \alpha)$ radiation. The UV-vis diffuse reflectance spectra (DRS) of samples were measured with Hitachi U-4100 UV-vis spectrophotometer. The photoluminescence (PL) spectra were tested with an FLS 920 FluorescencLe spectrometer at room temperature.

\subsection{Photocatalytic evaluation}

The photocatalytic activity of samples was evaluated by the degradation of Rhodamine $\mathrm{B}$ (RhB). In experiments, $0.1 \mathrm{~g}$ samples were added to $100 \mathrm{~mL}$ aqueous solution of RhB $(10 \mathrm{mg}$ $\mathrm{L}^{-1}$ ) in a BL-GHX photochemical reactor (Shanghai Bilon Instrument. ltd. China). A $500 \mathrm{~W}$ Xe lamp was used as the visiblelight source with $420 \mathrm{~nm}$ cut-off filter. Before irradiation, the suspension was kept in the dark under stirring for $30 \mathrm{~min}$ to ensure an adsorption-desorption equilibrium. After a given irradiation, about $4 \mathrm{~mL}$ suspension was collected, centrifuged and analyzed immediately. The RhB concentration were analyzed by a UV-vis spectrometer (Agilent 8453, USA) at 554. The TOC concentration was analyzed by Shimadzu TOC-LCPN analyzer. The degradation efficiency (\%) was calculated as follows:

$$
\text { Degradation }(\%)=\frac{\left(C_{0}-C\right)}{C_{0}} \times 100 \%
$$

where $C_{0}$ is the initial concentration of $\mathrm{RhB}$, and $C$ is the timedependent concentration of RhB upon irradiation.

\section{Results and discussion}

\subsection{XRD analyses}

The crystal structures of the as-synthesized samples were examined by XRD patterns. Fig. 1 shows the XRD patterns of 


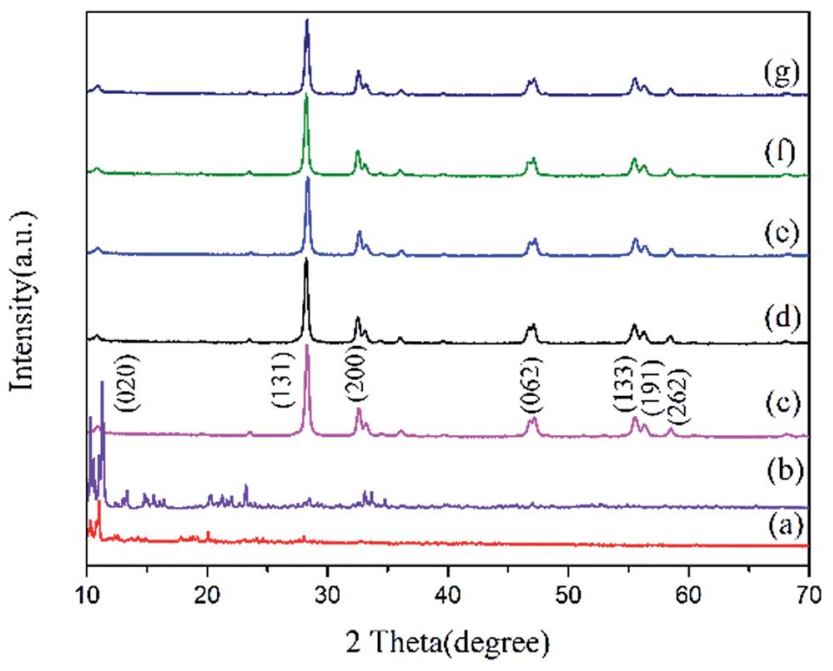

Fig. 1 XRD patterns of (a) MIL-100(Fe), (b) MIL-100(Fe)-simulated, (c) $\mathrm{Bi}_{2} \mathrm{MoO}_{6}$, (d) $\mathrm{Bi}_{2} \mathrm{MoO}_{6}-\mathrm{MIL}-100$ (Fe)-3, (e) $\mathrm{Bi}_{2} \mathrm{MoO}_{6}-\mathrm{MIL}-100$ (Fe)-6, (f) $\mathrm{Bi}_{2} \mathrm{MoO}_{6}-\mathrm{MIL}-100$ (Fe)-9, (g) $\mathrm{Bi}_{2} \mathrm{MoO}_{6}-\mathrm{MIL}-100$ (Fe)-12.

$\mathrm{Bi}_{2} \mathrm{MoO}_{6}$, and $\mathrm{Bi}_{2} \mathrm{MoO}_{6}-\mathrm{MIL}-100(\mathrm{Fe})$ composites with different contents of MIL-100(Fe). For comparison, the patterns of pure MIL-100(Fe), $\mathrm{Bi}_{2} \mathrm{MoO}_{6}$ as well as simulated MIL-100(Fe) are also shown. These distinct diffraction peaks at $2 \theta=10.85,28.2,32.5$, 46.7 and $55.5^{\circ}$, can be attributed to the (020), (131), (200), (062) and (133) crystal planes of pure $\mathrm{Bi}_{2} \mathrm{MoO}_{6}$ (JCPDS 76-2388). The diffraction peaks of pure MIL-100(Fe) sample can match with simulated MIL-100(Fe), the XRD result indicated the structure of pure MIL- $100(\mathrm{Fe})$ sample is intact. For the $\mathrm{Bi}_{2} \mathrm{MoO}_{6}-\mathrm{MIL}$ $100(\mathrm{Fe})$ samples (Fig. 1d-g), all diffraction peaks indexed to the orthorhombic $\mathrm{Bi}_{2} \mathrm{MoO}_{6}$ phase are clearly observed. However, no peak in samples assigned to MIL-100(Fe) was observed, possibly due to the low content and high dispersion of MIL-100(Fe). In addition, no impurity was observed. With the increase of MIL-100(Fe) contents, the intensities of peaks for $\mathrm{Bi}_{2} \mathrm{MoO}_{6}$ get reduced.

\subsection{Morphology}

Fig. 2 shows the SEM images of $\mathrm{Bi}_{2} \mathrm{MoO}_{6}, \mathrm{MIL}-100(\mathrm{Fe})$ and their composites $\mathrm{Bi}_{2} \mathrm{MoO}_{6}-\mathrm{MIL}-100(\mathrm{Fe})-9$, respectively. The rough microspheres composed of nanoparticles with dozens of nanometers are observed for $\mathrm{Bi}_{2} \mathrm{MoO}_{6}$ (Fig. 2a). And the diameter of the microsphere is $1-3 \mu \mathrm{m}$. In the Fig. $2 \mathrm{~b}$, the pure MIL100(Fe) exhibited regular octahedron morphology with diameter ranging from 2 to $4 \mu \mathrm{m}$. As for the $\mathrm{Bi}_{2} \mathrm{MoO}_{6}-\mathrm{MIL}-100(\mathrm{Fe})-9$ composite (Fig. 2c and d), it can be observed that MIL-100(Fe) serves as a support and the nanoparticles of $\mathrm{Bi}_{2} \mathrm{MoO}_{6}$ grow on the surface of MIL-100(Fe). Meanwhile, there is no aggregation of $\mathrm{Bi}_{2} \mathrm{MoO}_{6}$ nanoparticles on MIL-100(Fe), indicating that the interaction between $\mathrm{Bi}_{2} \mathrm{MoO}_{6}$ and $\mathrm{MIL}-100(\mathrm{Fe})$ is strong. Besides, the regular octahedron morphology of MIL-100(Fe) was not changed in the composite, the result demonstrated the structure of MIL-100(Fe) was not destroyed in the synthesized process of $\mathrm{Bi}_{2} \mathrm{MoO}_{6}-\mathrm{MIL}-100(\mathrm{Fe})$ composite. The Energy Dispersive Spectroscopy (EDS) patterns of $\mathrm{Bi}_{2} \mathrm{MoO}_{6}-\mathrm{MIL}$ -
100(Fe)-9 composite revealed the existence of $\mathrm{Bi}, \mathrm{Mo}, \mathrm{C}, \mathrm{O}$ and Fe. The tight interaction between the $\mathrm{Bi}_{2} \mathrm{MoO}_{6}$ and MIL-100(Fe) can enhance the photocatalytic activity.

The TEM and HRTEM images of $\mathrm{Bi}_{2} \mathrm{MoO}_{6}-\mathrm{MIL}-100(\mathrm{Fe})-9$ sample were shown in Fig. 3a and b, respectively. The TEM image shows the $\mathrm{Bi}_{2} \mathrm{MoO}_{6}$ nanoparticles on the MIL-100(Fe) surface, and the microstructures of the $\mathrm{Bi}_{2} \mathrm{MoO}_{6}-\mathrm{MIL}-100(\mathrm{Fe})$ 9 sample. The HRTEM images clearly indicated the resolved lattice fringes of $0.315,0.406$ and $0.192 \mathrm{~nm}$, which correspond to the (131), (040) and (062) planes of orthorhombic phase of $\mathrm{Bi}_{2} \mathrm{MoO}_{6}$, respectively. The results indicate that the formation of composites of $\mathrm{Bi}_{2} \mathrm{MoO}_{6}$ and $\mathrm{MIL}-100(\mathrm{Fe})$ can promote faster separation of photoinduced charge carriers and improve photocatalytic activities.

\subsection{XPS analysis}

The surface chemical composition of $\mathrm{Bi}_{2} \mathrm{MoO}_{6}-\mathrm{MIL}-100(\mathrm{Fe})-9$ was analyzed by XPS. Fig. 4 shows XPS survey spectra and high-resolution XPS spectra of the Bi 4f, Mo 3d, O 1s, Fe 2p and $\mathrm{C} 1 \mathrm{~s}$ regions for the sample of $\mathrm{Bi}_{2} \mathrm{MoO}_{6}-\mathrm{MIL}-100(\mathrm{Fe})-9$. The survey spectra indicated that $\mathrm{Bi}, \mathrm{Mo}, \mathrm{O}, \mathrm{Fe}$ and $\mathrm{C}$ exist on the surface of $\mathrm{Bi}_{2} \mathrm{MoO}_{6}-\mathrm{MIL}-100(\mathrm{Fe})-9$, and no impurities were detected, in accordance with EDS result. In the $\mathrm{Bi} 4 \mathrm{f}$ spectrum, two peaks at $159.2 \mathrm{eV}$ and $164.5 \mathrm{eV}$ are attributed to $\mathrm{Bi} 4 \mathrm{f}_{7 / 2}$ and $\mathrm{Bi} 4 \mathrm{f}_{5 / 2}$ of $\mathrm{Bi}^{3+}$, respectively. ${ }^{33}$ In the Mo $3 \mathrm{~d}$ spectrum, peaks at

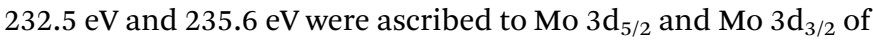
$\mathrm{Mo}^{6+}$, respectively. ${ }^{34}$ The $\mathrm{O} 1 \mathrm{~s}$ peak of the composite at $530.1 \mathrm{eV}$ is observed, which was relate to Mo-O. ${ }^{35}$ The Fe $2 \mathrm{p}$ peak was associated with the binding energy at $712.1 \mathrm{eV}$, which are characteristic of $\mathrm{Fe}(\mathrm{III})$ in $\mathrm{MIL}-100(\mathrm{Fe}) \cdot{ }^{31}$ In addition, the $\mathrm{C} 1 \mathrm{~s}$ peaks at 288.8 and $284.7 \mathrm{eV}$ arises from MIL-100(Fe) and external carbon contamination, respectively. ${ }^{36}$ In summary, the XPS spectra analysis confirms that $\mathrm{Bi}_{2} \mathrm{MoO}_{6}-\mathrm{MIL}-100(\mathrm{Fe})$ composites have been synthesized successfully.

\subsection{BET analysis}

Brunauer-Emmett-Teller (BET) surface area of the assynthesized samples were examined by nitrogen adsorptiondesorption isotherms at $77 \mathrm{~K}$. It can be found that the introduction of MIL-100(Fe) can significantly affect the BET surface area of samples. Compared with pure $\mathrm{Bi}_{2} \mathrm{MoO}_{6}$, the BET surface area $\left(S_{\mathrm{BET}}\right)$ of $\mathrm{Bi}_{2} \mathrm{MoO}_{6}-\mathrm{MIL}-100(\mathrm{Fe})$ composites obviously increased, from $9.3172 \mathrm{~m}^{2} \mathrm{~g}^{-1}$ to $109.6347 \mathrm{~m}^{2} \mathrm{~g}^{-1}$. The larger surface area of photocatalysts can provide more surface active sites and promote charge carriers transport easily, contributing to an enhanced photocatalytic performance. ${ }^{37}$ Therefore, MIL-100(Fe) in synthesized composites may play the key role in enhancing the photocatalytic activity.

\subsection{PL analysis}

Photoluminescence (PL) spectra were used to investigate the transfer and separation efficiency of photogenerated electronhole pairs. ${ }^{38}$ As we all known, the lower PL intensity indicated a lower recombination of photoinduced charge carriers. The PL spectra of $\mathrm{Bi}_{2} \mathrm{MoO}_{6}$, MIL-100(Fe) and $\mathrm{Bi}_{2} \mathrm{MoO}_{6}-\mathrm{MIL}-100(\mathrm{Fe})-9$ for excitation wavelength $605 \mathrm{~nm}$ are shown in Fig. 5. The 

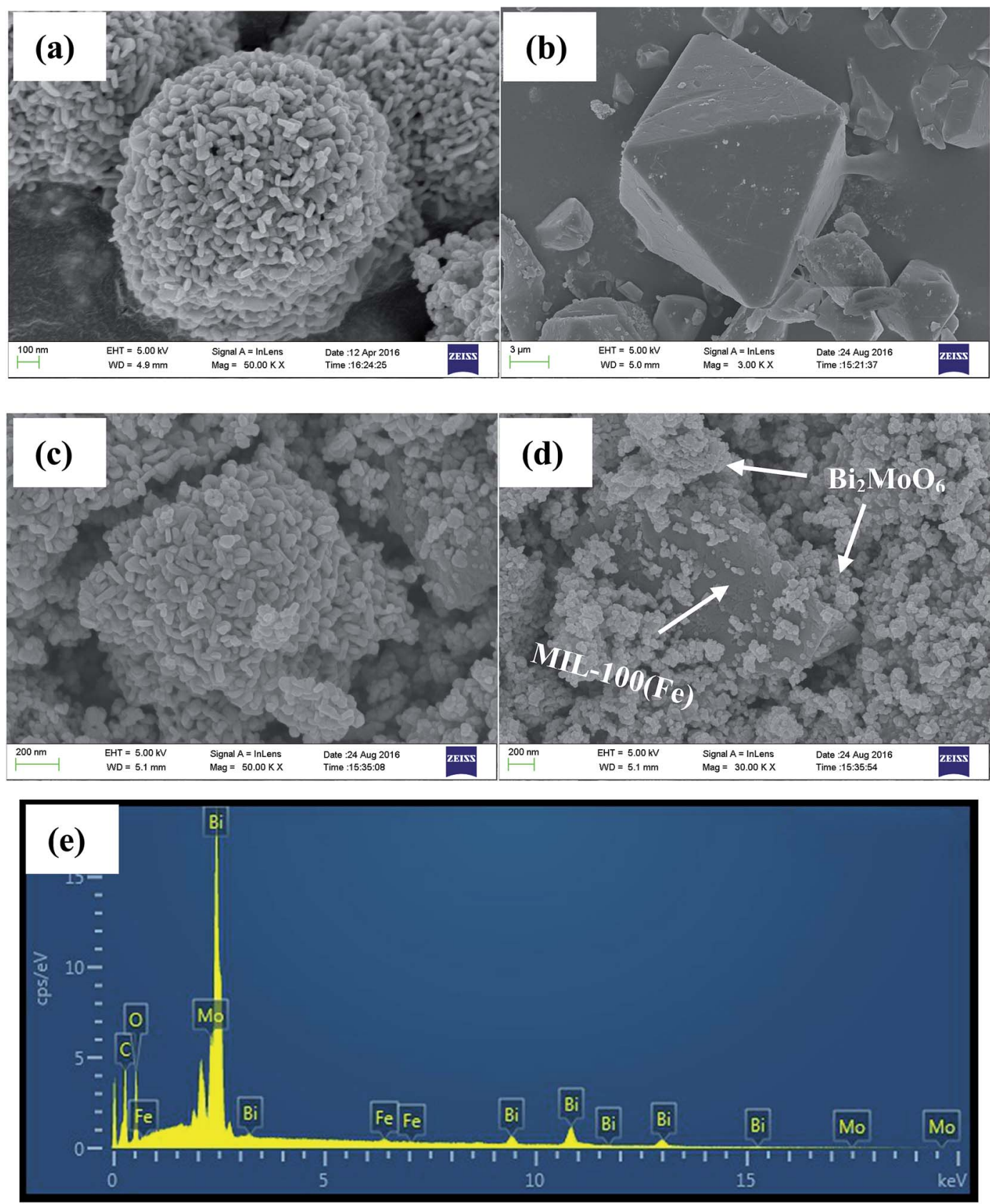

Fig. 2 SEM images of (a) pure $\mathrm{Bi}_{2} \mathrm{MoO}_{6}$, (b) pure MIL-100(Fe), (c) and (d) $\mathrm{Bi}_{2} \mathrm{MoO}_{6}-\mathrm{MIL}-100(\mathrm{Fe})-9$ composites, and (e) EDS patterns of the $\mathrm{Bi}_{2} \mathrm{MoO}_{6}-\mathrm{MIL}-100(\mathrm{Fe})-9$ composites.

main emission peaks around $460-500 \mathrm{~nm}$ appear for three photocatalysts, and the emission peak of $\mathrm{Bi}_{2} \mathrm{MoO}_{6}-\mathrm{MIL}-100(\mathrm{Fe})$ 9 is lower than the $\mathrm{Bi}_{2} \mathrm{MoO}_{6}$ and MIL-100(Fe). The resulting of the PL spectra indicated the addition of MIL-100(Fe) into semiconductor $\mathrm{Bi}_{2} \mathrm{MoO}_{6}$ is contributed to the separation of photo-generated electron-hole pairs.

\subsection{UV-vis DRS}

The UV-vis diffusive reflectance spectra (UV-vis DRS) of $\mathrm{Bi}_{2} \mathrm{MoO}_{6}, \mathrm{MIL}-100(\mathrm{Fe})$ and $\mathrm{Bi}_{2} \mathrm{MoO}_{6}-\mathrm{MIL}-100(\mathrm{Fe})-9$ photocatalysts were shown in Fig. 6a. The adsorption of three photocatalytic samples are located in visible light region. The absorption edge of $\mathrm{Bi}_{2} \mathrm{MoO}_{6}$ is $485 \mathrm{~nm}$, and MIL-100(Fe) exhibits absorption edge in $550 \mathrm{~nm}$. As the composites of two different semiconductors, the $\mathrm{Bi}_{2} \mathrm{MoO}_{6}-\mathrm{MIL}-100(\mathrm{Fe})-9$ exhibits absorption edges at $510 \mathrm{~nm}$. Furthermore, the band gap energies of $\mathrm{Bi}_{2} \mathrm{MoO}_{6}$ and MIL-100(Fe) could be calculated by the following equation: ${ }^{39}$

$$
\alpha(h v)=A\left(h v-E_{\mathrm{g}}\right)^{1 / 2}
$$

where $\alpha, v, E_{\mathrm{g}}$, and $A$ are the absorption coefficient, the light frequency, the energy band gap of semiconductor, and 


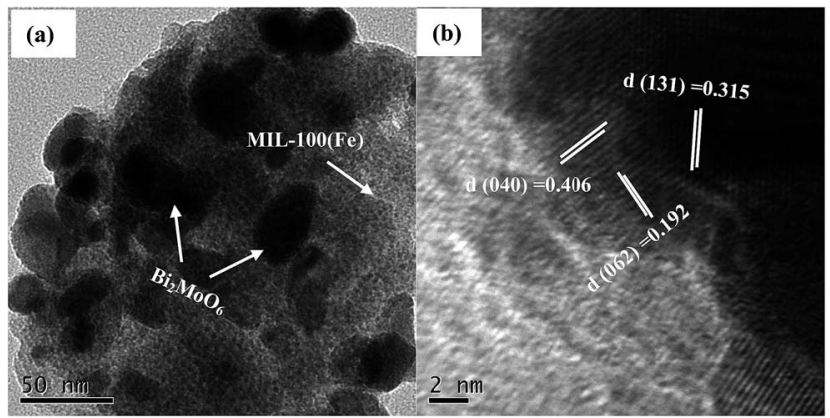

Fig. 3 (a) TEM and (b) HRTEM images of $\mathrm{Bi}_{2} \mathrm{MoO}_{6}-\mathrm{MIL}-100(\mathrm{Fe})-9$.

a constant, respectively. According to eqn (2), the band-gap of photocatalysts can be estimated from plots of $(\alpha h v)^{2}$ versus energy $(h v)$. In the Fig. 6b, the band gaps of as-synthesized $\mathrm{Bi}_{2} \mathrm{MoO}_{6}, \mathrm{MIL}-100(\mathrm{Fe})$ and $\mathrm{Bi}_{2} \mathrm{MoO}_{6}-\mathrm{MIL}-100(\mathrm{Fe})-9$ are estimated to be $2.58,2.50$ and $2.38 \mathrm{eV}$, respectively. The resulting confirmed that $\mathrm{Bi}_{2} \mathrm{MoO}_{6}$ can match up with MIL-100(Fe)

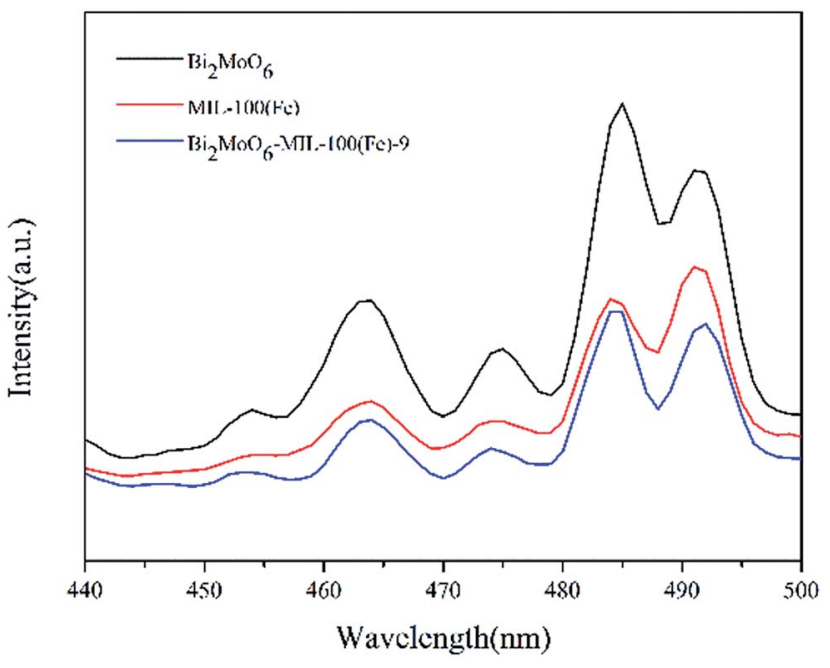

Fig. $5 \mathrm{PL}$ spectra of $\mathrm{Bi}_{2} \mathrm{MoO}_{6}, \mathrm{MIL}-100(\mathrm{Fe})$ and $\mathrm{Bi}_{2} \mathrm{MoO}_{6}-\mathrm{MIL}-$ $100(\mathrm{Fe})-9$, recorded at an excitation wavelength of $605 \mathrm{~nm}$.
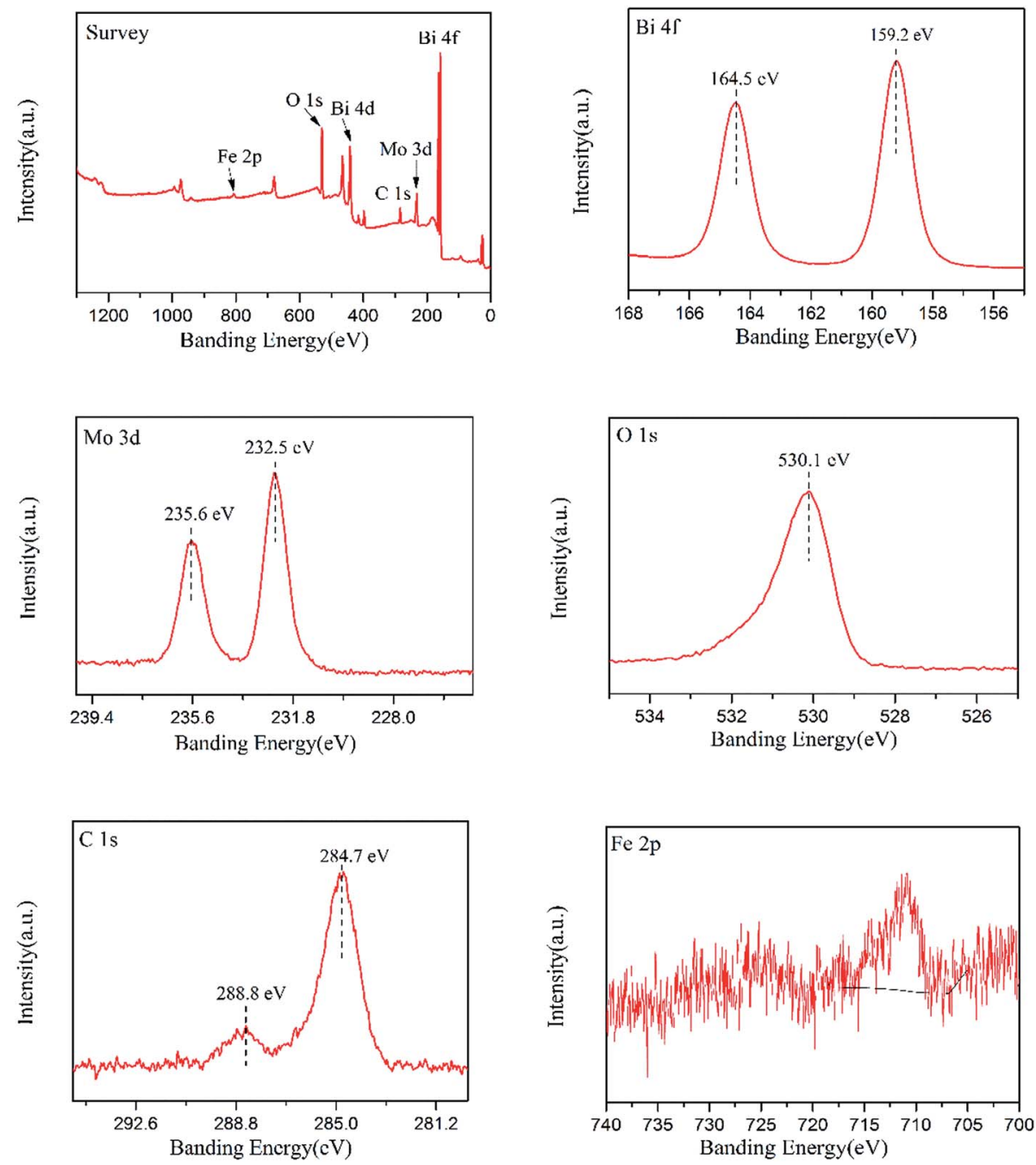

Fig. 4 XPS survey spectra of $\mathrm{Bi}_{2} \mathrm{MoO}_{6}-\mathrm{MIL}-100$ (Fe)-9 and high-resolution XPS spectra of the $\mathrm{Bi} 4 \mathrm{f}, \mathrm{Mo} 3 \mathrm{~d}, \mathrm{O} 1 \mathrm{~s}, \mathrm{Fe} 2 \mathrm{p}$ and C $1 \mathrm{~s}$. 
(a)

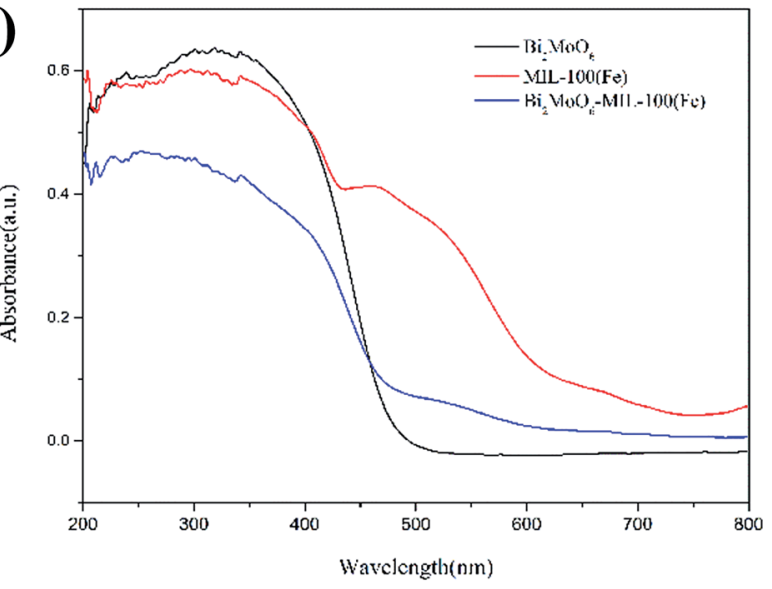

(b)

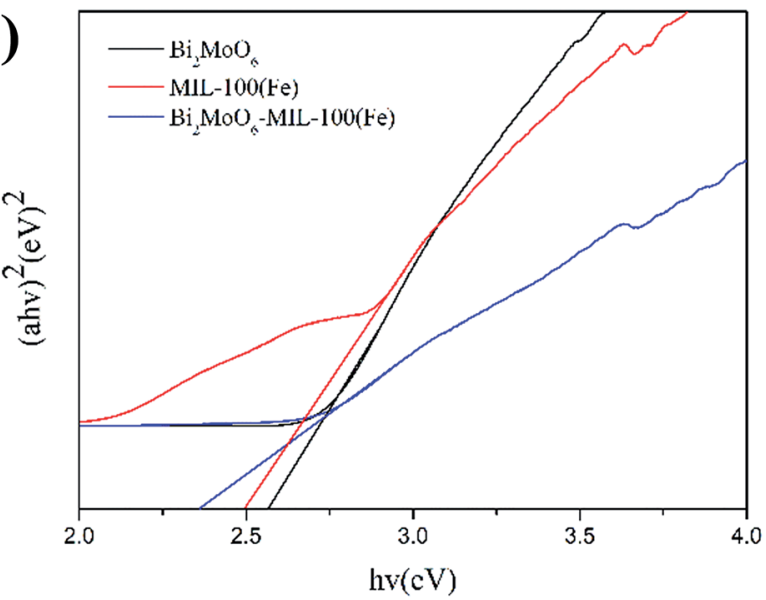

Fig. 6 (a) UV-vis diffuse reflectance spectra (DRS) of $\mathrm{Bi}_{2} \mathrm{MoO}_{6}, \mathrm{MIL}$ 100(Fe) and $\mathrm{Bi}_{2} \mathrm{MoO}_{6}-\mathrm{MIL}-100(\mathrm{Fe})-9 ;$ (b) the plots of $(a h v)^{n / 2} \mathrm{vs}$. photon energy $(h v)$ for the band-gap energies of $\mathrm{Bi}_{2} \mathrm{MoO}_{6}$, MIL$100(\mathrm{Fe})$ and $\mathrm{Bi}_{2} \mathrm{MoO}_{6}-\mathrm{MIL}-100(\mathrm{Fe})-9$.

perfectly, which contributes to the separation of the electronhole pairs.

\subsection{Photocatalytic activity}

The photocatalytic activities of as-prepared photocatalysts were evaluated by the degradation of RhB under visible light irradiation. The RhB adsorption and photodegradation process of different photocatalysts are shown in Fig. 7a. Before the visible light irradiation, the absorption-desorption balance has been reached between the catalyst and $\mathrm{RhB}$ for $30 \mathrm{~min}$ absorption process. Fig. 7a shows that RhB was hardly decomposed by photolysis without any catalysts under visible light irradiation. The adsorption rate of pure $\mathrm{Bi}_{2} \mathrm{MoO}_{6}$ and MIL-100(Fe) are $15.36 \%$ and $44.39 \%$ in the dark, respectively. The adsorption rate of MIL-100(Fe) is very high, but it has low photocatalytic performance for $\mathrm{RhB}$ under the visible-light irradiation. Meanwhile, pure $\mathrm{Bi}_{2} \mathrm{MoO}_{6}$ shows low photocatalytic activity for $\mathrm{RhB}$ degradation, the photodegradation rate is $62.56 \%$.
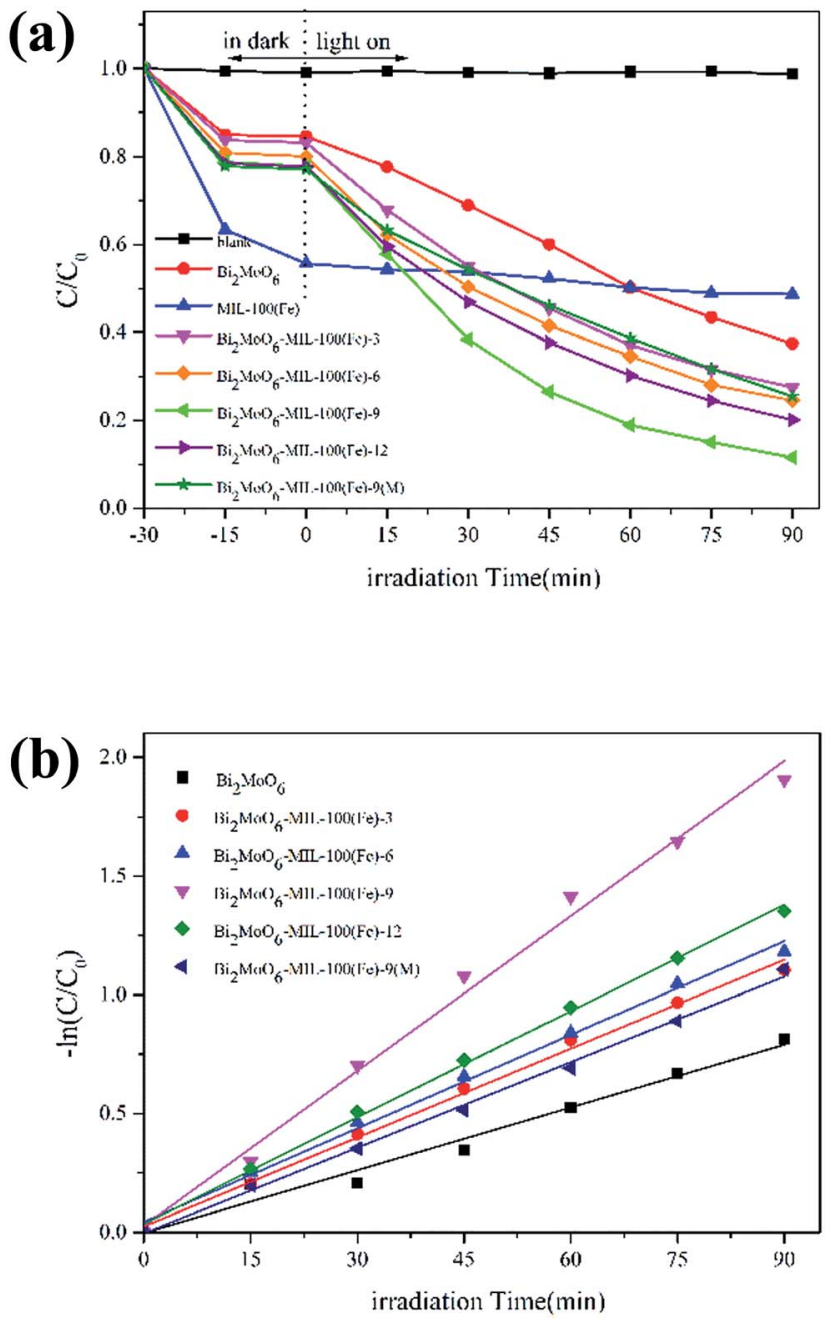

Fig. 7 (a) Photodegradation of as-prepared samples for RhB. (b) The kinetic constants $(k)$ of photocatalytic for RhB.

However, the addition of MIL-100(Fe) improved the photocatalytic activities of $\mathrm{Bi}_{2} \mathrm{MoO}_{6}-\mathrm{MIL}-100(\mathrm{Fe})$ composites significantly. The photocatalytic activities of $\mathrm{Bi}_{2} \mathrm{MoO}_{6}-\mathrm{MIL}-100(\mathrm{Fe})$ composites enhanced, with the increase of content of MIL$100(\mathrm{Fe})$. When the addition of MIL-100(Fe) reached $9 \%$, $\mathrm{Bi}_{2} \mathrm{MoO}_{6}-\mathrm{MIL}-100(\mathrm{Fe})$ composites demonstrated greater degradation performance, up to $88.46 \% \mathrm{RhB}$ removed in $120 \mathrm{~min}$. Meanwhile, the absorption of RhB in $\mathrm{Bi}_{2} \mathrm{MoO}_{6}-\mathrm{MIL}-100(\mathrm{Fe})-9$ increased to $22.25 \%$ compared with pure $\mathrm{Bi}_{2} \mathrm{MoO}_{6}$, indicating that the introduction of MIL-100(Fe) promoted the increase of adsorption ability of catalysts. Besides, the physical mixture $\mathrm{Bi}_{2} \mathrm{MoO}_{6}-\mathrm{MIL}-100(\mathrm{Fe})-9(\mathrm{M})$ composite exhibited lower activity than $\mathrm{Bi}_{2} \mathrm{MoO}_{6}-\mathrm{MIL}-100(\mathrm{Fe})-9$, it may be due to the instable $\mathrm{Bi}_{2} \mathrm{MoO}_{6}-\mathrm{MIL}-100(\mathrm{Fe})$ heterojunctions. The result indicated that the presence of MIL-100(Fe) enhanced light absorption, separation of photo-generated electron-hole pairs, and increased surface area. The enhanced photocatalytic performance is contributed to the heterostructure between $\mathrm{Bi}_{2} \mathrm{MoO}_{6}$ and MIL-100(Fe). In addition, Fig. 7b shows the corresponding first-order kinetics plot by the equation: ${ }^{40}$ 


$$
-\ln \left(C / C_{0}\right)=k t
$$

where $C_{0}$ and $C$ are the $\mathrm{RhB}$ concentrations in solution at times 0 and $t$, respectively, and $k$ is the apparent first-order rate constant. According to the equation, the rates of $\mathrm{RhB}$ degradation are $0.00881 \mathrm{~min}^{-1}, 0.01248 \mathrm{~min}^{-1}, 0.01314 \mathrm{~min}^{-1}$, $0.02174 \mathrm{~min}^{-1}, 0.01494 \mathrm{~min}^{-1}$ and $0.01201 \mathrm{~min}^{-1}$ for pure $\mathrm{Bi}_{2} \mathrm{MoO}_{6}, \quad \mathrm{Bi}_{2} \mathrm{MoO}_{6}-\mathrm{MIL}-100(\mathrm{Fe})-3, \quad \mathrm{Bi}_{2} \mathrm{MoO}_{6}-\mathrm{MIL}-100(\mathrm{Fe})-6$, $\mathrm{Bi}_{2} \mathrm{MoO}_{6}-\mathrm{MIL}-100$ (Fe)-9, $\mathrm{Bi}_{2} \mathrm{MoO}_{6}-\mathrm{MIL}-100(\mathrm{Fe})-12$ and $\mathrm{Bi}_{2} \mathrm{MoO}_{6}-$ MIL-100(Fe)-9(M). The rate of RhB degradation of $\mathrm{Bi}_{2} \mathrm{MoO}_{6}-\mathrm{MIL}$ $100(\mathrm{Fe})-9$ is higher than other photocatalysts. The result indicated that the interaction between $\mathrm{Bi}_{2} \mathrm{MoO}_{6}$ and MIL-100(Fe) can improve the photocatalytic performance, and the photocatalytic activity is significantly enhancing with the increase of the mass ratio of MIL-100(Fe). The photocatalytic activity reached the maximum value, when the mass ratio of MIL-100(Fe) is $9 \%$.

The mineralization rate of RhB over photocatalysts was detected by Total Organic Carbon (TOC) test. The TOC results (Fig. 8) indicated that only $67.42 \%$ of $\mathrm{RhB}$ is mineralized over $\mathrm{Bi}_{2} \mathrm{MoO}_{6}-\mathrm{MIL}-100(\mathrm{Fe})-9$ after $120 \mathrm{~min}$ and more irradiation time is needed to make the substrate completely mineralized. After $210 \mathrm{~min}$, the mineralization rate of $\mathrm{RhB}$ over $\mathrm{Bi}_{2} \mathrm{MoO}_{6}$ MIL-100(Fe)-9 can only reach $87.29 \%$. But the mineralization rate of $\mathrm{RhB}$ over $\mathrm{Bi}_{2} \mathrm{MoO}_{6}-\mathrm{MIL}-100(\mathrm{Fe})-9$ is higher than that over $\mathrm{Bi}_{2} \mathrm{MoO}_{6}$ and $\mathrm{Bi}_{2} \mathrm{MoO}_{6}-\mathrm{MIL}-100(\mathrm{Fe})-9(\mathrm{M})$. The above results show that $\mathrm{Bi}_{2} \mathrm{MoO}_{6}-\mathrm{MIL}-100(\mathrm{Fe})$ composites exhibited much higher photocatalytic performance than pure $\mathrm{Bi}_{2} \mathrm{MoO}_{6}$ under visible light irradiation.

\subsection{The proposed photocatalytic mechanism}

3.8.1 Analysis of active species. The active species including holes $\left(\mathrm{h}^{+}\right)$, superoxide radical $\left({ }^{\cdot} \mathrm{O}_{2}{ }^{-}\right)$, and hydroxyl radicals $\left({ }^{\circ} \mathrm{OH}\right)$ are possibly impact factors for the photodegradation of organic pollutants. It is important to carry out the trapping experiments for confirming the main active species generated over $\mathrm{Bi}_{2} \mathrm{MoO}_{6}-$ MIL-100(Fe) composites. In the detection, EDTA-2Na (ref. 33) and tert-butyl alcohol (TBA) $)^{41}$ are used as the scavengers of holes $\left(\mathrm{h}^{+}\right)$

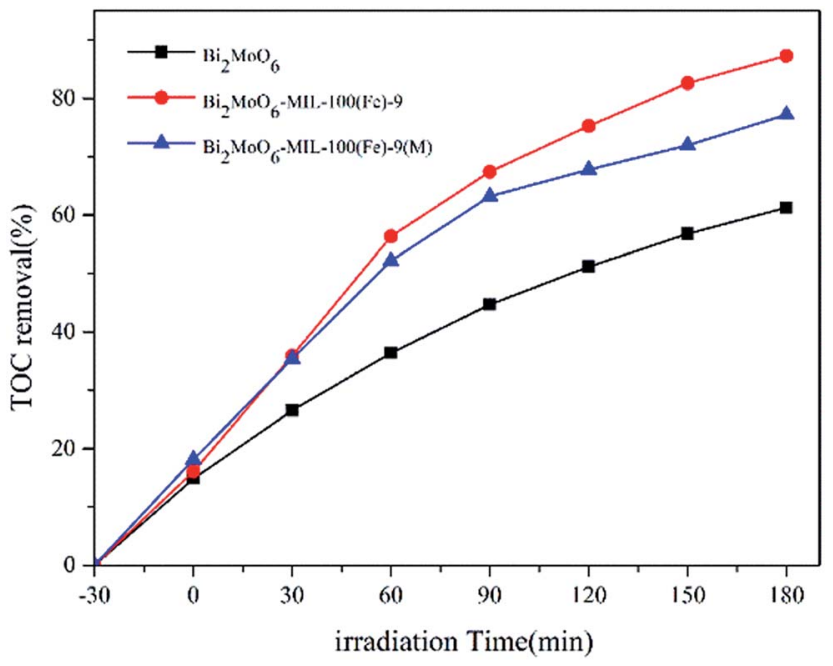

Fig. 8 TOC removal process of RhB solution. and hydroxyl radical $\left({ }^{\circ} \mathrm{OH}\right)$. The $p$-benzoquinone $(\mathrm{BQ})^{42}$ and $\mathrm{N}_{2}$ (ref. 43) are used as the scavenger of superoxide radical $\left({ }^{\circ} \mathrm{O}_{2}{ }^{-}\right)$. As shown in Fig. 9, the photocatalytic degradation of RhB over $\mathrm{Bi}_{2} \mathrm{MoO}_{6}-\mathrm{MIL}-100(\mathrm{Fe})-9$ was slightly affected by the addition of TBA $(1 \mathrm{~mL})$. However, the photocatalytic activity of $\mathrm{Bi}_{2} \mathrm{MoO}_{6}-$ MIL-100(Fe)-9 was significantly inhibited by the addition of EDTA-2Na (0.5 mmol). Similarly, the degradation rate was obviously decreased after the addition of BQ $(0.5 \mathrm{mmol})$. In the word, active species including $\mathrm{h}^{+}$and ${ }^{\circ} \mathrm{O}_{2}{ }^{-}$play the crucial roles in the photodegradation of pollutants.

To test the role of dissolved $\mathrm{O}_{2}$ in the reaction process, enough nitrogen $\left(\mathrm{N}_{2}\right)$ was bubbled into the suspension to ensure that the degradation system was operated under anoxic conditions. In the presence of $\mathrm{N}_{2}$, the photocatalytic activity of catalyst was inhibited under the same condition. This result means that dissolved $\mathrm{O}_{2}$ is a vital factor in $\mathrm{RhB}$ removal over $\mathrm{Bi}_{2} \mathrm{MoO}_{6}-\mathrm{MIL}-100(\mathrm{Fe})$ composites, which affects the formation of ${ }^{\circ} \mathrm{O}_{2}{ }^{-}$via direct reduction of $\mathrm{O}_{2}$ and the formation of ${ }^{\circ} \mathrm{OH}$ via indirect reduction of $\mathrm{O}_{2}{ }^{44}$

3.8.2 The proposed photocatalytic mechanism. It is wellknown that the photocatalytic performances of catalysts rely on the transfer, separation and generation of electron-hole pairs. In our study, the interaction between $\mathrm{Bi}_{2} \mathrm{MoO}_{6}$ and MIL$100(\mathrm{Fe})$ can promote the separation of photogenerated charge carries and improve the photodegradation rate under visible light. In order to understand the photocatalytic mechanism of the $\mathrm{Bi}_{2} \mathrm{MoO}_{6}-\mathrm{MIL}-100(\mathrm{Fe})$ composites in depth, the initial energy band structures of $\mathrm{Bi}_{2} \mathrm{MoO}_{6}$ and MIL-100(Fe) were estimated. The band edges of $\mathrm{Bi}_{2} \mathrm{MoO}_{6}$ and MIL-100(Fe) were calculated by the following empirical formulas: ${ }^{45}$

$$
\begin{gathered}
E_{\mathrm{VB}}=X-E_{\mathrm{e}}+0.5 E_{\mathrm{g}} \\
E_{\mathrm{CB}}=E_{\mathrm{VB}}-E_{\mathrm{g}}
\end{gathered}
$$

where $E_{\mathrm{VB}}$ is the valence band (VB) edge potential, $E_{\mathrm{CB}}$ is the conduction band edge potential, $E_{\mathrm{g}}$ is the band gap energy of the semiconductor, $X$ is the electronegativity of the

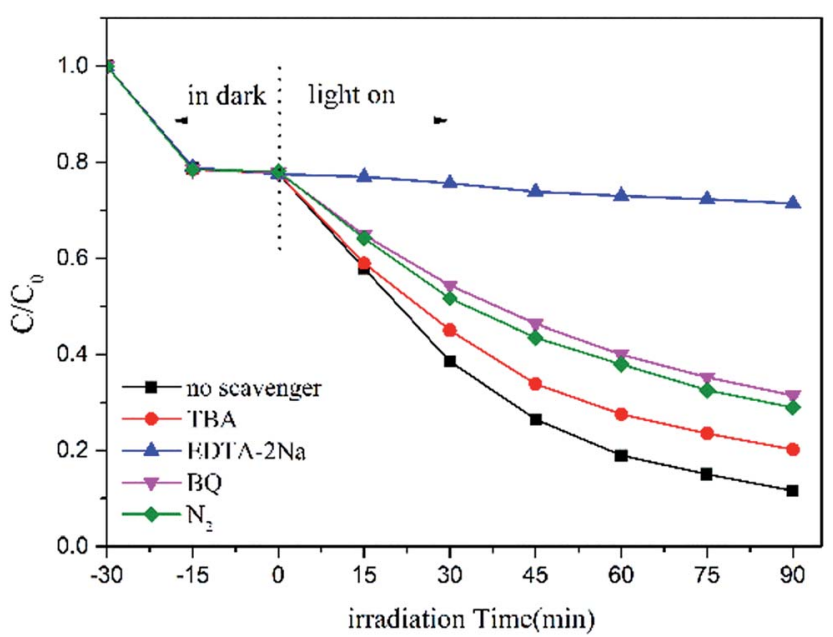

Fig. 9 Photocatalytic degradation of $\mathrm{RhB}$ over $\mathrm{Bi}_{2} \mathrm{MoO}_{6}-\mathrm{MIL}-$ $100(\mathrm{Fe})-9$ with different scavengers. 
semiconductor, which is the geometric mean of the electronegativity of the constituent atoms, and the $X$ values for $\mathrm{Bi}_{2} \mathrm{MoO}_{6}$ and MIL-100(Fe) were calculated to be 5.55 and $5.10 \mathrm{eV}$, respectively. $E_{\mathrm{e}}$ is the energy of free electrons on the hydrogen scale (about $4.5 \mathrm{eV}$ ). The $E_{\mathrm{g}}$ of $\mathrm{Bi}_{2} \mathrm{MoO}_{6}$ and MIL-100(Fe) are estimated as 2.58 and $2.50 \mathrm{eV}$. According to above formulas, the VB and $\mathrm{CB}$ edge potentials of $\mathrm{Bi}_{2} \mathrm{MoO}_{6}$ are located at -0.24 and $2.34 \mathrm{eV}$, respectively. The $\mathrm{VB}$ and $\mathrm{CB}$ edge potentials of MIL-100(Fe) are determined to be -0.65 and $1.85 \mathrm{eV}$, respectively.

On the basis of above band energy level analysis and active species trapping detection, the possible proposed mechanism was discussed as illustrated in Scheme 1. Under the visible light irradiation, both $\mathrm{Bi}_{2} \mathrm{MoO}_{6}$ and MIL-100(Fe) can be excited for generation of electrons $\left(\mathrm{e}^{-}\right)$and holes $\left(\mathrm{h}^{+}\right)$in their $\mathrm{CB}$ and VB. The photo-generated electrons in the CB of MIL-100(Fe) transfer to the $\mathrm{CB}$ of $\mathrm{Bi}_{2} \mathrm{MoO}_{6}$ via the heterojunction structure. At the same, the holes in the $\mathrm{VB}$ of $\mathrm{Bi}_{2} \mathrm{MoO}_{6}$ can migrate to the $\mathrm{VB}$ of MIL-100(Fe), hence promoting the separation of photoinduced electron-holes pairs. $\mathrm{O}_{2}$ molecules in solution adsorbed onto catalysts form superoxide radical $\left({ }^{\circ} \mathrm{O}_{2}{ }^{-}\right)$via electron transfer from MIL-100(Fe) to $\mathrm{O}_{2}$, since the conduction band potential of MIL-100(Fe) $(-0.65$ eV versus $\mathrm{NHE})$ was more negative than the standard redox potentials of $\left(E\left(\mathrm{O}_{2} /{ }^{\cdot} \mathrm{O}_{2}{ }^{-}\right)=-0.33 \mathrm{eV}\right.$ versus NHE). Similarly, the standard redox potentials of $\left(E\left(\mathrm{H}_{2} \mathrm{O} /{ }^{\circ} \mathrm{OH}\right)=\right.$ $+2.8 \mathrm{eV}$ versus NHE) was more positive than the $\mathrm{VB}$ of the $\mathrm{Bi}_{2} \mathrm{MoO}_{6}(2.34 \mathrm{eV})$ and MIL-100(Fe) $(1.85 \mathrm{eV})$, thus it is difficult to oxidize the adsorbed $\mathrm{H}_{2} \mathrm{O}$ into ${ }^{\circ} \mathrm{OH}$ for photo-generated. The part $\mathrm{h}^{+}$radicals reacted with $\mathrm{H}_{2} \mathrm{O}$ molecules in solution to generate reactive hydroxyl $\left({ }^{\circ} \mathrm{OH}\right)$ and $\mathrm{H}^{+}$ions. Moreover, the adsorbed $\mathrm{RhB}$ onto $\mathrm{Bi}_{2} \mathrm{MoO}_{6}-\mathrm{MIL}-100(\mathrm{Fe})$ can be excited to $\mathrm{RhB}^{*}$ under visible-light irradiation. ${ }^{46}$ Then the electrons from $\mathrm{RhB}^{*}$ are transformed into photocatalyst to form $\mathrm{RhB}^{+\bullet}$. The $\mathrm{RhB}$ (or $\mathrm{RhB}^{+\bullet}$ ) is finally photodegraded by the reactive species $\left(\mathrm{O}_{2},{ }^{\circ} \mathrm{OH}\right)$ or $\mathrm{h}^{+}$to generate $\mathrm{H}_{2} \mathrm{O}$ and $\mathrm{CO}_{2}$. According to above discussion, the process can be described as follows:

$$
\begin{gathered}
\text { MIL-100(Fe) }+h v \rightarrow \text { MIL-100(Fe) }\left(\mathrm{e}^{-}+\mathrm{h}^{+}\right) \\
\mathrm{RhB}+h v \rightarrow \mathrm{RhB}^{*} \rightarrow \mathrm{RhB}^{+\cdot}+\mathrm{e}^{-} \\
\mathrm{Bi}_{2} \mathrm{MoO}_{2}+\mathrm{e}^{-} \rightarrow \mathrm{Bi}_{2} \mathrm{MoO}_{2}\left(\mathrm{e}^{-}+\mathrm{h}^{+}\right)
\end{gathered}
$$

$$
\begin{gathered}
\text { MIL-100(Fe) }\left(\mathrm{e}^{-}\right)+\mathrm{O}_{2} \rightarrow \mathrm{O}^{-}+\mathrm{MIL}-100(\mathrm{Fe}) \\
\mathrm{O}_{2}{ }^{-}+\mathrm{RhB} / \mathrm{RhB}^{+\cdot} \rightarrow \text { other products } \rightarrow \mathrm{CO}_{2}+\mathrm{H}_{2} \mathrm{O} \\
\cdot \mathrm{OH}+\mathrm{RhB} / \mathrm{RhB}^{+\cdot} \rightarrow \text { other products } \rightarrow \mathrm{CO}_{2}+\mathrm{H}_{2} \mathrm{O} \\
\mathrm{h}^{+}+\mathrm{RhB} / \mathrm{RhB}^{+\cdot} \rightarrow \text { other products } \rightarrow \mathrm{CO}_{2}+\mathrm{H}_{2} \mathrm{O}
\end{gathered}
$$

\subsection{Regeneration and reusability}

It is significant to evaluate the reusable performance and stability of photocatalysts for practical applications. ${ }^{47}$ To investigate the stability of $\mathrm{Bi}_{2} \mathrm{MoO}_{6}-\mathrm{MIL}-100(\mathrm{Fe})-9$, we carried out 4 times recycle experiment to degrade $\mathrm{RhB}$ under the same conditions. After each cycle, the photocatalyst was centrifuged, filtered, washed and dried at $60{ }^{\circ} \mathrm{C}$ for $12 \mathrm{~h}$. As shown in Fig. 10a, after four cycles, the degradation rate of RhB decreased from $88.46 \%$ to $84.91 \%$, the photocatalyst removed organic pollutants with only a slight loss of activity. After being used four times, as shown in Fig. 10b, the XRD patterns of $\mathrm{Bi}_{2} \mathrm{MoO}_{6}$ MIL-100(Fe)-9 composite before and after catalytic reaction further demonstrated that the structure of the $\mathrm{Bi}_{2} \mathrm{MoO}_{6}-\mathrm{MIL}$ 100(Fe) composites remain intact. Besides, the ICP-AES analysis showed that the leaching $\mathrm{Fe}$ and $\mathrm{Bi}$ ions from the photocatalysts in the reaction solution were $0.143 \mathrm{mg} \mathrm{L}^{-1}$ and less than $0.01 \mathrm{mg} \mathrm{L}^{-1}$ after cycles reaction respectively. The leaching ions concentration is very low compared with the concentration of catalysts $\left(1000 \mathrm{mg} \mathrm{L}^{-1}\right)$, which is negligible. Therefore, the as-prepared $\mathrm{Bi}_{2} \mathrm{MoO}_{6}-\mathrm{MIL}-100(\mathrm{Fe})-9$ composites show excellent stability and reusability in the visible light photochemical applications.

\section{Conclusions}

In summary, $\mathrm{Bi}_{2} \mathrm{MoO}_{6}-\mathrm{MIL}-100(\mathrm{Fe})$ photocatalysts have been successfully fabricated by facile solvothermal method in this work for the first time. The characterizations of $\mathrm{Bi}_{2} \mathrm{MoO}_{6}-\mathrm{MIL}-$ 100(Fe) composites were confirmed by XRD, SEM/EDS, TEM, and XPS. The as-synthesized $\mathrm{Bi}_{2} \mathrm{MoO}_{6}-\mathrm{MIL}-100(\mathrm{Fe})$ photocatalyst exhibited excellent photocatalytic performance in degradation of RhB under visible light. The optimal mass ratio

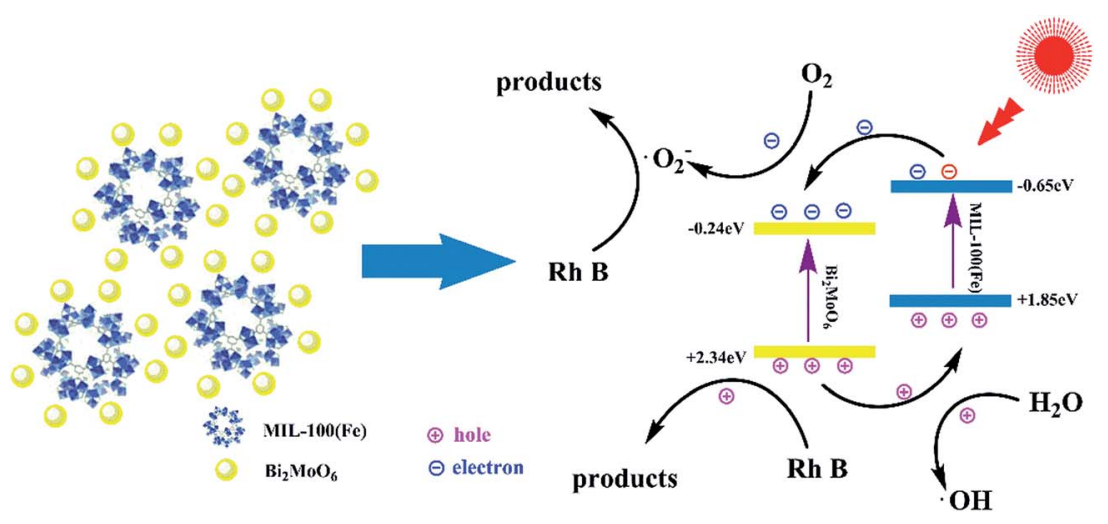

Scheme 1 Photocatalytic degradation mechanism over $\mathrm{Bi}_{2} \mathrm{MoO}_{6}-\mathrm{MIL}-100$ (Fe) heterostructure under visible light irradiation. 
(a)

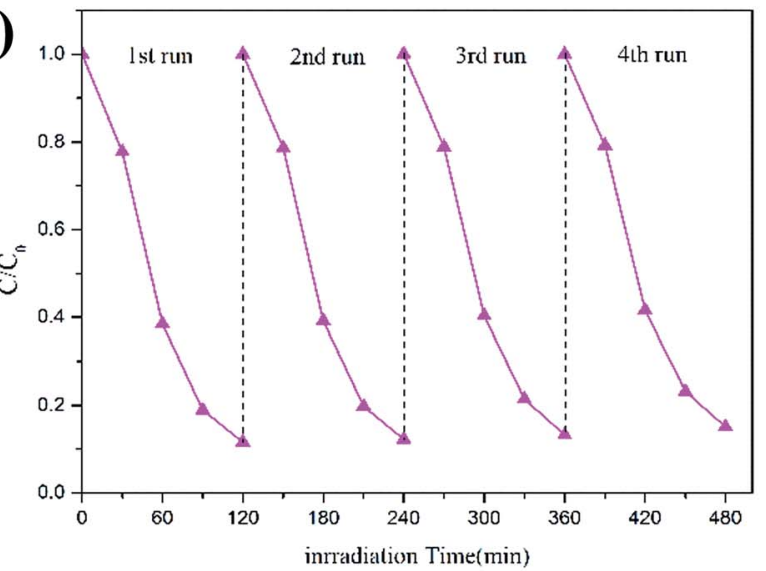

(b)

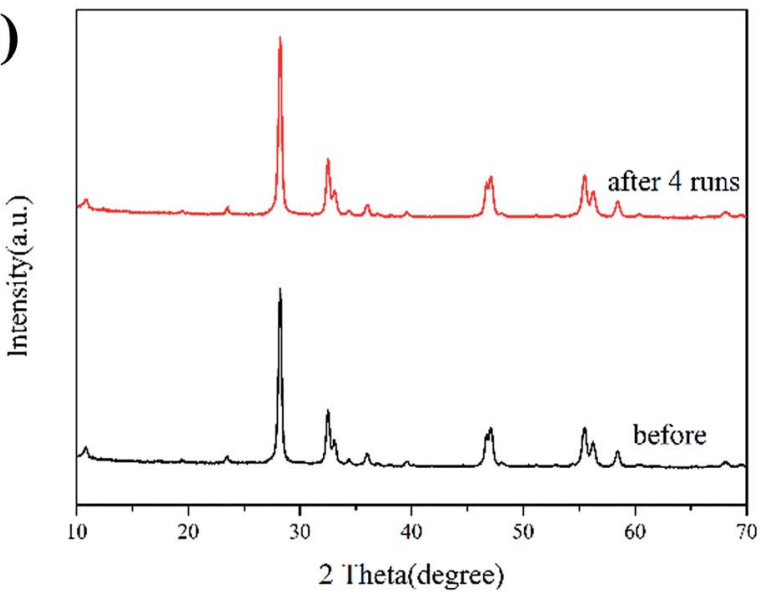

Fig. 10 (a) Cycling runs for photocatalytic degradation of RhB over $\mathrm{Bi}_{2} \mathrm{MoO}_{6}-\mathrm{MIL}-100$ (Fe)-9 under visible light irradiation; (b) XRD patterns of $\mathrm{Bi}_{2} \mathrm{MoO}_{6}-\mathrm{MIL}-100(\mathrm{Fe})-9$ before and after reactions.

of MIL-100(Fe) in the composite is $9 \%$ for the excellent synergistic effect between $\mathrm{Bi}_{2} \mathrm{MoO}_{6}$ and MIL-100(Fe). The presence of MIL-100(Fe) in the composites enhanced light absorption, and increased surface area. The photo-generated $\mathrm{h}^{+}$and ${ }^{\circ} \mathrm{O}_{2}{ }^{-}$in $\mathrm{Bi}_{2} \mathrm{MoO}_{6}-\mathrm{MIL}-100(\mathrm{Fe})$ composites are proved to be the main active species over the photodegradation. The enhanced photocatalytic performance is mainly attributed to perfect matched energy band of heterostructure, improved photoinduced charge carriers transfer efficiency, and inhibited photo-generated electron-hole recombination. Our study confirmed that the introduction of $\mathrm{MIL}-100(\mathrm{Fe})$ into semiconductor $\mathrm{Bi}_{2} \mathrm{MoO}_{6}$ can improve the photocatalytic activity and stability of $\mathrm{Bi}_{2} \mathrm{MoO}_{6}$ based photocatalysts, it may be a promising candidate in synthesis of novel catalysts.

\section{Acknowledgements}

This work was supported by the State Key Laboratory of Lake Science and Environment (2016SKL011).

\section{References}

1 H. Li, J. Liu, W. Hou, N. Du, R. Zhang and X. Tao, Appl. Catal., $B$, 2014, 160-161, 89-97.

2 M. Andersson, L. Österlund, S. Ljungström and A. Palmqvist, J. Phys. Chem. B, 2002, 106, 10674-10679.

3 G. Li, X. Nie, Y. Gao and T. An, Appl. Catal., B, 2016, 180, 726732.

4 Z. F. Yin, L. Wu, H. G. Yang and Y. H. Su, Phys. Chem. Chem. Phys., 2013, 15, 4844-4858.

5 L. Zhang, T. Xu, X. Zhao and Y. Zhu, Appl. Catal., B, 2010, 98, 138-146.

6 S. Cao, X. Liu, Y. Yuan, Z. Zhang, Y. Liao, J. Fang, S. C. J. Loo, T. C. Sum and C. Xue, Appl. Catal., B, 2014, 147, 940-946.

7 Y. Xu and W. Zhang, Dalton Trans., 2013, 42, 1094-1101.

8 S. Martha, A. Nashim and K. M. Parida, J. Mater. Chem. A, 2013, 1, 7816.

9 M. Mạczka, L. Macalik, K. Hermanowicz, L. Kepiński and J. Hanuza, J. Raman Spectrosc., 2010, 41, 1289-1296.

10 K. Dai, D. Li, L. Geng, C. Liang and Q. Liu, Mater. Lett., 2015, 160, 124-127.

11 X. Lin, X. Guo, D. Liu, Q. Wang, H. Zhai and L. Chang, Mater. Res. Bull., 2015, 63, 72-79.

12 Z. Dai, F. Qin, H. Zhao, J. Ding, Y. Liu and R. Chen, ACS Catal., 2016, 6, 3180-3192.

13 Y. Feng, X. Yan, C. Liu, Y. Hong, L. Zhu, M. Zhou and W. Shi, Appl. Surf. Sci., 2015, 353, 87-94.

14 J. Lv, K. Dai, J. Zhang, L. Geng, C. Liang, Q. Liu, G. Zhu and C. Chen, Appl. Surf. Sci., 2015, 358, 377-384.

15 T. Yan, M. Sun, H. Liu, T. Wu, X. Liu, Q. Yan, W. Xu and B. Du, J. Alloys Compd., 2015, 634, 223-231.

16 P. Wang, Y. Ao, C. Wang, J. Hou and J. Qian, Carbon, 2012, 50, 5256-5264.

17 A. Phuruangrat, S. Putdum, P. Dumrongrojthanath, N. Ekthammathat, S. Thongtem and T. Thongtem, Mater. Sci. Semicond. Process., 2015, 34, 175-181.

18 L. Shen, S. Liang, W. Wu, R. Liang and L. Wu, J. Mater. Chem. A, 2013, 1, 11473.

19 M. D. Allendorf, R. J. T. Houk, L. Andruszkiewicz, A. A. Talin, J. Pikarsky, A. Choudhury, K. A. Gall and P. J. Hesketh, J. Am. Chem. Soc., 2008, 130, 14404-14405.

20 R. B. Getman, Y. Bae, C. E. Wilmer and R. Q. Snurr, Chem. Rev., 2012, 112, 703-723.

21 P. Horcajada, R. Gref, T. Baati, P. K. Allan, G. Maurin, P. Couvreur, G. Férey, R. E. Morris and C. Serre, Chem. Rev., 2012, 112, 1232-1268.

22 L. Yang, P. Ravindran, P. Vajeeston and M. Tilset, Phys. Chem. Chem. Phys., 2012, 14, 4713.

23 I. Luz, F. X. Llabrés I Xamena and A. Corma, J. Catal., 2010, 276, 134-140.

24 D. Jiang, T. Mallat, F. Krumeich and A. Baiker, J. Catal., 2008, 257, 390-395.

25 M. Dan-Hardi, C. Serre, T. Frot, L. Rozes, G. Maurin, C. Sanchez and G. Férey, J. Am. Chem. Soc., 2009, 131, 10857-10859.

26 H. Wang, X. Yuan, Y. Wu, G. Zeng, H. Dong, X. Chen, L. Leng, Z. Wu and L. Peng, Appl. Catal., B, 2016, 186, 19-29. 
27 J. He, Z. Yan, J. Wang, J. Xie, L. Jiang, Y. Shi, F. Yuan, F. Yu and Y. Sun, Chem. Commun., 2013, 49, 6761.

28 F. Ke, L. Wang and J. Zhu, Nano Res., 2015, 8, 1834-1846.

29 X. Wang, J. Liu, S. Leong, X. Lin, J. Wei, B. Kong, Y. Xu, Z. Low, J. Yao and H. Wang, ACS Appl. Mater. Interfaces, 2016, 8, 9080-9087.

30 D. Esken, S. Turner, C. Wiktor, S. B. Kalidindi, G. Van Tendeloo and R. A. Fischer, J. Am. Chem. Soc., 2011, 133, 16370-16373.

31 R. Liang, S. Luo, F. Jing, L. Shen, N. Qin and L. Wu, Appl. Catal., B, 2015, 176-177, 240-248.

32 D. Kim, H. Kim and D. Cho, Catal. Commun., 2016, 73, 6973.

33 Y. Feng, X. Yan, C. Liu, Y. Hong, L. Zhu, M. Zhou and W. Shi, Appl. Surf. Sci., 2015, 353, 87-94.

34 Z. Zhao, W. Zhang, Y. Sun, J. Yu, Y. Zhang, H. Wang, F. Dong and Z. Wu, J. Phys. Chem. C, 2016, 120, 11889-11898.

35 H. Li, Q. Deng, J. Liu, W. Hou, N. Du, R. Zhang. T. Xutang, 2014.

36 F. Zhang, Y. Jin, J. Shi, Y. Zhong, W. Zhu and M. S. El-Shall, Chem. Eng. J., 2015, 269, 236-244.
37 L. Shen, S. Liang, W. Wu, R. Liang and L. Wu, J. Mater. Chem. A, 2013, 1, 11473.

38 D. Yue, T. Zhang, M. Kan, X. Qian and Y. Zhao, Appl. Catal., $B, 2016,183,1-7$.

39 J. Lv, K. Dai, J. Zhang, L. Geng, C. Liang, Q. Liu, G. Zhu and C. Chen, Appl. Surf. Sci., 2015, 358, 377-384.

40 S. Fang, C. Ding, Q. Liang, Z. Li, S. Xu, Y. Peng and D. Lu, J. Alloys Compd., 2016, 684, 230-236.

41 J. Cao, B. Xu, H. Lin, B. Luo and S. Chen, Dalton Trans., 2012, 41, 11482.

42 X. Xiong, L. Ding, Q. Wang, Y. Li, Q. Jiang and J. Hu, Appl. Catal., B, 2016, 188, 283-291.

43 Y. Yao, J. Qin, H. Chen, F. Wei, X. Liu, J. Wang and S. Wang, J. Hazard. Mater., 2015, 291, 28-37.

44 R. Jiang, H. Y. Zhu, J. B. Li, F. Q. Fu, J. Yao, S. T. Jiang and G. M. Zeng, Appl. Surf. Sci., 2016, 364, 604-612.

45 J. Tian, P. Hao, N. Wei, H. Cui and H. Liu, ACS Catal., 2015, 5, 4530-4536.

46 X. Yuan, H. Wang, Y. Wu, G. Zeng, X. Chen, L. Leng, Z. Wu and H. Li, Appl. Organomet. Chem., 2016, 30, 289-296.

47 S. Martha, A. Nashim and K. M. Parida, J. Mater. Chem. A, 2013, 1, 7816. 